Research Paper

\title{
Halotolerance, ligninase production and herbicide degradation ability of basidiomycetes strains
}

\author{
R.L. Arakaki, D.A. Monteiro, M. Boscolo, R. Dasilva, E. Gomes \\ Laboratório de Bioquímica Aplicada, Instituto de Biociências, Letras e Ciências Exatas, \\ Universidade Estadual Paulista "Júlio de Mesquita Filho", São José do Rio Preto, SP, Brazil.
}

Submitted: August 13, 2012; Approved: April 4, 2013.

\begin{abstract}
Fungi have been recently recognized as organisms able to grow in presence of high salt concentration with halophilic and halotolerance properties and their ligninolytic enzyme complex have an unspecific action enabling their use to degradation of a number of xenobiotic compounds. In this work, both the effect of salt and polyols on growth of the basidiomycetes strains, on their ability to produce ligninolytic enzyme and diuron degradation were evaluated. Results showed that the presence of $\mathrm{NaCl}$ in the culture medium affected fungal specimens in different ways. Seven out of ten tested strains had growth inhibited by salt while Dacryopinax elegans SXS323, Polyporus sp MCA128 and Datronia stereoides MCA167 fungi exhibited higher biomass production in medium containing 0.5 and $0.6 \mathrm{~mol} . \mathrm{L}^{-1}$ of $\mathrm{NaCl}$, suggesting to be halotolerant. Polyols such as glycerol and mannitol added into the culture media improved the biomass and ligninases production by D. elegans but the fungus did not reveal consumption of these polyols from media. This fungus degraded diuron in medium control, in presence of $\mathrm{NaCl}$ as well as polyols, produced $\mathrm{MnP}$, LiP and laccase.
\end{abstract}

Key words: basidiomycetes, halotolerance, ligninases, diuron degradation.

\section{Introduction}

The ability to growth and the mechanisms involved in adaptation to low water activity $\left(\mathrm{a}_{\mathrm{w}}\right)$ has been well understood for prokaryote groups. However, only in the last decade fungi were isolated from saline and hypersaline environments (Moubasher et al., 1990; Cantrell et al., 2006) but their adjustment mechanisms to halophile conditions is still not clear. Two proteins, in the membrane and in the cytoplasm (HwHhk7 and HwSho1) have been reported to act as osmosensors in halophile fungus which is a signal for cascade of the MAPKs, leading to phosphorylation of Hog 1 that is translocated into the nucleus, regulating the expression of a number of genes involved in salt tolerance (Gostinc et al., 2011). Lenassi et al. (2011) described differences among adaptive, obligate halophiles and salt-sensitive fungi at the molecular level involving enzyme as glycerol-3-phosphate dehydrogenase Gpd1.

Sometimes, high salinity of the medium containing xenobiotics can difficult the biodegradation process, affect- ing the growth and activities of microorganisms (Petrovic et al., 2002; Abou-Elela et al., 2010). In this way, the utilization of salt-tolerant organisms in biological treatment could be an interesting approach. A successful degradation of xenobiotics by halotolerant Penicillium spp, Trametes and Flavodon flavus (Leitão et al., 2005; Cantrell et al., 2010) has been described.

The increasing in the use of agricultural chemicals results in the accumulation of these compounds and their derivatives in soil and water. Diuron is a phenylurea herbicide (N-(3,4-dichlorophenyl)-N,N-dimethylurea; CAS 33054-1) and it is one of the most often employed agrochemicals for controlling weeds in sugarcane, citrus and coffee crops. It has high mobility in soils, low susceptibility to natural attenuation and strong toxicity. Besides, more toxic metabolites with genotoxic and teratogenic actions such as 3,4-dichloroanilines, N-3,4-dichlorophenylurea and N(3,4-dichlorophenyl)-N-methylurea can be generated from diuron by biotic and abiotic reactions (Tixier et al., 2000; Dellamatrice and Monteiro, 2004; Giacomazzi and Cochet,

Send correspondence to E. Gomes. Laboratory of Biochemistry and Applied Microbiology, Ibilce, Universidade Estadual Paulista "Júlio de Mesquita Filho", São José do Rio Preto, SP, Brazil. E-mail: eleni@ibilce.unesp.br. 
2004). The dissipation of phenylurea herbicides in the environment was reported as a predominantly biological process, suggesting that the restoration of polluted sites through bioremediation is a promising tool (Cameron et al., 2000; Sørensen et al., 2003).

Fungi from basidiomycetes group are referred by reason of their noticeable versatility to oxidize a wide range of xenobiotic, phenolic or non-phenolic compounds (Cerniglia, 1997), dyes (Trovaslet et al., 2007), pesticides (Gianfreda and Rao, 2004), chlorophenols and organophosphorus (Keum and Li, 2004). The mechanisms consist of carbon bond breakage with aromatic ring fission, aryl-alkyl breakage and lateral chains removal.

In spite of their ability to degrade several compounds, a few strains of basidiomycetes were evaluated in relation to their salt-tolerance. Therefore, the aim of this work was to investigate the effect of $\mathrm{NaCl}$ concentration on the ability of basidiomycetes species to grow, produce ligninases and degrade herbicide diuron.

\section{Materials and Methods}

\section{Fungal cultures}

Ten basidiomycetes strains, previously isolated from decaying wood in the Atlantic Rainforest fragments, at "Estação Ecológica do Noroeste Paulista", northeast of São Paulo State, Brazil (Santos et al., 2004; Abrahão et al., 2008) were used in this work. The fungi were being preserved using Castellani's method, under mineral oil and liquid Nitrogen.

\section{Culture medium, inoculum and cultivation condition}

Mycelium was scraped from agar plates, under sterile conditions, and transferred to $120 \mathrm{~mL}$ Erlenmeyer flasks loosely capped with cotton plugs, containing $50 \mathrm{~mL}$ of the basal medium composed of $\left(\mathrm{g} . \mathrm{L}^{-1}\right): 5.0$ glucose, 2.0 yeast extract, 1.0 potassium sodium tartrate, 1.0 ammonium phosphate monobasic, 0.5 magnesium sulfate, 0.2 potassium chloride and $1.0 \mathrm{~mL}$ of micronutrient solution. The $\mathrm{pH}$ was adjusted to 5.5. After growing for 6-7 days, at $28^{\circ} \mathrm{C}$, the medium was removed and the mycelium washed twice with Knapp buffer (Tixier et al., 2000). After that, fungal biomass was mixed with the buffer in a sterile mixer, and cell suspension was diluted to reach the optical density of 0.5 at the wavelength of $550 \mathrm{~nm}$. This suspension was used as inoculum for experiments using the same medium. The incubation was carried out for 10 days at $28^{\circ} \mathrm{C}$.

\section{Culture conditions for halotolerance, effect of mannitol and glycerol on growth and diuron degradation}

In order to evaluate the tolerance of the fungi to salt concentrations, the culture medium was supplemented with 0.5, 0.6 and 0.8 mol. $\mathrm{L}^{-1}$ of $\mathrm{NaCl}$. The effect of addition of mannitol and glycerol at $0.5 \mathrm{M}$ to the culture medium was also studied. For diuron degradation experiments, a commercial formulation of diuron $\operatorname{Karmex}^{\circledR}$ (dupont) was employed in culture medium. The pesticide was diluted in methanol $\left(12.5 \mathrm{mg} \cdot \mathrm{mL}^{-1}\right)$, homogenized by two sonication pulses of $15 \mathrm{~min}$ and centrifuged at $10,000 \mathrm{~g}$ for $10 \mathrm{~min}$ at $10{ }^{\circ} \mathrm{C}$. Then, the solution was sterilized by filtration through a $0.22 \mu \mathrm{m}$ Millipore membrane. Aliquots were dispensed into sterile $125 \mathrm{~mL}$ flasks in a laminar flow. After solvent evaporation, each one received $25 \mathrm{~mL}$ of sterile liquid culture medium previously described, resulting in final concentration of 5 and $10 \mathrm{mg} . \mathrm{L}^{-1}$ of diuron. Diuron dissipation and ligninolytic enzyme production were evaluated for until 10 days in slight agitation at $28^{\circ} \mathrm{C}$, in the dark. At the end of the cultivation period, cultures were centrifuged at $10,000 \mathrm{~g}$ for $10 \mathrm{~min}$ and the mycelium was dried at $70^{\circ} \mathrm{C}$ to quantification of both biomass and the filtered used for determination of diuron degradation.

\section{HPLC analysis}

All media samples were centrifuged and afterwards filtered through a $0.22 \mu \mathrm{m}$ membrane. Diuron degradation rates were estimated using an isocratic Jasco HPLC, employing a UV-975 detector adjusted to $240 \mathrm{~nm}$ and a starchromatography 4.0 Varian software. Analyses were developed with a C18 (Perkin Elmer) column, in an oven stated at $40{ }^{\circ} \mathrm{C}$. The pesticides were eluted by a degassed mobile phase composed of acetonitrile and water $\left(60 / 40 \mathrm{v} \cdot \mathrm{v}^{-1}\right)$, with a flow rate of $1 \mathrm{~mL} \cdot \mathrm{min}^{-1}$. As standard for calibration curve diuron Ultrachem was employed $(99 \%$ purity). All samples were injected three times and the results represent the means taken.

\section{Enzyme assays}

Enzymatic activities in the crude extract of fungal cultures were determined spectrophotometrically, by reactions carried out at $40^{\circ} \mathrm{C}$. Laccase (EC 1.10.3.2) was measured based on ABTS (Sigma) oxidation $\left(\varepsilon=3.6 .10^{4} \mathrm{M}^{-1}\right.$ $\mathrm{cm}^{-1}$ ), at $420 \mathrm{~nm}$ Buswell et al. (1984). Lignin peroxidase (EC 1.11.1.14) (LiP) activity was estimated by means of veratryl alcohol (Fluka) oxidation to veratraldehyde $\left(\varepsilon=9.3 \cdot 10^{3} \mathrm{M}^{-1} \mathrm{~cm}^{-1}\right)$ at $310 \mathrm{~nm} \mathrm{Li}$ et al. (2003). Manganese-dependent peroxidase (EC 1.11.1.13) (MnP) had its activity determined by generation of lactate- $\mathrm{Mn}^{3+}$ complexes $\left(\varepsilon=8.1 .10^{3} \mathrm{M}^{-1} \mathrm{~cm}^{-1}\right)$, absorbing at $240 \mathrm{~nm}$ (Glenn et al., 1986; Aitken and Irvine, 1990). For all cases, 1 unit of enzymatic activity was expressed as the amount of enzyme capable of oxidizing $1 \mu \mathrm{mol}$ of substrate per minute, under assay conditions, and expressed as $\mathrm{U}$ per gram of dry biomass.

\section{Analytical procedures}

Reducing sugars were determined by DNS method (Miller, 1959), using D-glucose as standard. The separation and identification of carbohydrate was carried out by 
HPAEC-PAD (ICS 3000, Dionex Corporation, EUA), with AS40 automated sampler and carbopac PA-1 anionic column. The standard quadruple $\mathrm{E}_{1}=0.10 \mathrm{~V}\left(\mathrm{t}_{1}=0.40 \mathrm{~s}\right)$; $\mathrm{E}_{2}=-2.00 \mathrm{~V}\left(\mathrm{t}_{2}=0.02 \mathrm{~s}\right) ; \mathrm{E}_{3}=0.60 \mathrm{~V}\left(\mathrm{t}_{3}=0,01 \mathrm{~s}\right) ; \mathrm{E}_{4}=$ $0.10 \mathrm{~V}\left(\mathrm{t}_{4}=0.06 \mathrm{~s}\right)$ was used. The flux was $1 \mathrm{~mL} \cdot \mathrm{min}^{-1}$. Glucose, glycerol and mannitol were the standard.

\section{Results and Discussion}

The evaluation of effect of $\mathrm{NaCl}$ at $0.5 \mathrm{~mol} . \mathrm{L}^{-1}$ on growth of fungi showed that the majority were sensitive to salt with strong inhibition of the growth, except for Dacrypionax elegans SXS323, Datronia stereoides MCA167 and Polyporus sp MA128 in which the presence of salt improved the biomass production in 90, 39 and 18\%, respectively (Table 1). Data from Figure 1 corroborate these results. Concentrations of 0.5 and 0.6 mol. $\mathrm{L}^{-1}$ of $\mathrm{NaCl}$ improved the growth of $D$. elegans, D. stereoides and Polyporus sp. in 100, 33 and 25\%, respectively. Furthermore, the three fungi were tolerant to $0.8 \mathrm{~mol} . \mathrm{L}^{-1}$ of the salt.

There is little information about the halophilic and halotolerant fungal specimens. According to Kirk et al. (2001), the tolerance to low $\mathrm{a}_{\mathrm{w}}$ was demonstrated for fungi from 10 orders among of 106 orders existing. In the Basidiomycota, three orders such as Wallemiales, Trichnosporales and Sporidiales have halophilic or halotolerant groups. While halotolerance is spread in several genus of these orders, a few obligate halophile genus are described. Yeast and yeast-like Rhodotorula, Debaryomyces, Aureobasidium, Trichosporum as well as filamentous fungi Cladosporium, Scopulariopsis, Alternaria, Aspergillus spp., Penicillium spp. are described as halotolerant. Halophilic spices are found in the genus Wallenia, Hortea, Phaetotheca, Trimmatostroma (Cantrell et al., 2006; Gunde-Cimerman et al., 2009). It was reported that basidiomycetes Microsporus xanthopus AN 24, Pycnoporus sanguineus Gc23 and GC67 and Schizophyllum commune Gc41, tolerates 35, 60 and 70 g. $\mathrm{L}^{-1}$ of $\mathrm{NaCl}$ Castillo and
Demoulin (1997). Phlebia sp tolerated 30 to 50\% (26) and Formitopis, 47 g.L -1 $^{-1}$ (Miyazaki et al., 2007; Li et al., 2002).

The establishment of limit between halotolerant and halophilic fungi is not straightforward. In prokaryote this limit has been clearly defined, that is to say, there are obligate halophilic microorganisms which require salt for optimal growth and, according to the concentration required, they can be categorized as extremely halophilic or moderately halophilic. Halotolerant microorganisms can survive and grow in high concentration of salt, although the best growth occurs in the absence of salt (Kivisto and Karp, 2011). It was reported that halophilic fungi do not require salt in order to grow, nor for the adjustment of cell activity and stability (Tangavelu et al., 2006; Plemennita et al., 2008). However, our results indicate that the basidiomycetes strains studied required salt for optimal growth and consequently could be considered as moderately halophilic.

\section{Effect of $\mathrm{NaCl}$, mannitol and glycerol on the growth and diuron degradation by $D$. elegans}

The ability of fungi to grow in medium with high salt concentration is an important tool for bioremediation, since industrial effluent frequently contains solute concentration that could inhibit enzymes and microorganisms sensitive to low $\mathrm{a}_{\mathrm{w}}$. On the other hand, crop soil, where herbicides are frequently used, can have its salinity increased by irrigation or by use of chemical fertilizer.

Considering that $D$. elegans required salt for growth and that polyol such as glycerol and mannitol have been described as osmolytes produced and/or accumulate by fungi as strategy for survival in environment with high salt concentration (Adler et al., 1985) this fungus was cultivated in medium containing sodium chloride, mannitol and glycerol and it growth and ability to degrade herbicide diuron was evaluated (Table 2).

Data from Figure 2a indicate that the growth of $D$. elegans was not affected by diuron, although the presence

Table 1 - Biomass production by basidiomycetes strains in media containing none or $0.5 \mathrm{Mol} . \mathrm{L}^{-1}$ of $\mathrm{NaCl}$ after $48 \mathrm{~h}$ of cultivation.

\begin{tabular}{lccc}
\hline & Control & NaCl $\left(0.5 \mathrm{Mol} \mathrm{L}^{-1}\right)$ & Improvement $(+)$ or inhibition $(-)$ of growth $(\%)$ \\
\hline Datronia Caperata MCA5 & $1.2 \pm 0.8$ & $0.1 \pm 0.08$ & -92 \\
Gloeophyllum striatum MCA7 & $2.5 \pm 0.3$ & $0.2 \pm 0.1$ & -92 \\
Hexagonia hirta MCA131 & $1.5 \pm 0.6$ & $0.25 \pm 0.09$ & -04 \\
Gloeophyllum striatum MCA2 & $1.8 \pm 0.5$ & $0.6 \pm 0.05$ \\
Pycnoporus sanguineus MCA16 & $2.3 \pm 0.8$ & $0.18 \pm 0.03$ \\
Polyporus tennuiculus MCA9 & $0.5 \pm 0.06$ & $0.5 \pm 0.09$ \\
Polyporus tenuiculus MCA11 & $1.0 \pm 0.2$ & $3.8 \pm 0.08$ \\
Dacrypionax elegans SXS323 & $2.0 \pm 0.04$ & $3.5 \pm 0.2$ \\
Datronia stereoides MCA167 & $2.6 \pm 0.4$ & -86 \\
Polyporus SP. MCA128 & $2.7 \pm 0.4$ & -50 \\
\hline
\end{tabular}


of both salt and diuron in the culture medium (Figure 2b) resulted in a lower biomass production suggesting therefore the increase in the sensitivity of fungi to herbicide in presence of salt. However when glycerol was added into the culture media, the biomass reached 7 g.L. ${ }^{-1}$ (Figure 2e), twice the maximum production obtained in medium where these compounds were absent.

Considering the high biomass production by fungus in medium in presence of glycerol, the remaining concentrations of this polyol in the culture medium in different phases of growth was determined. Figures $2 b$ shows that in

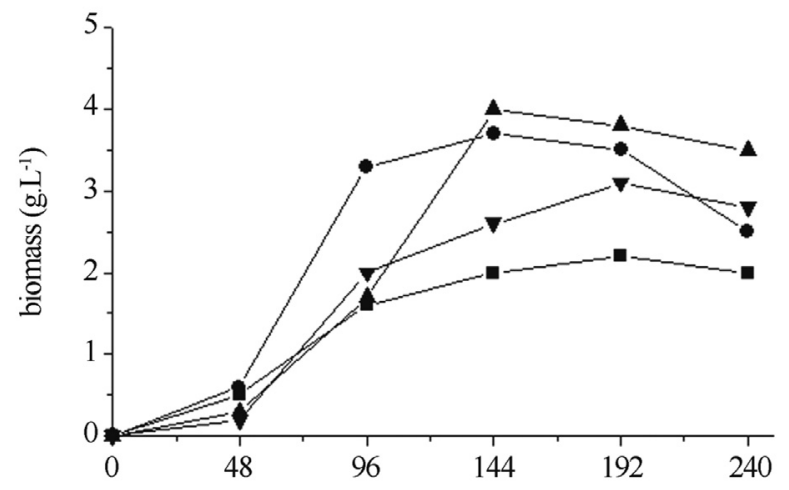

A

Time (h)

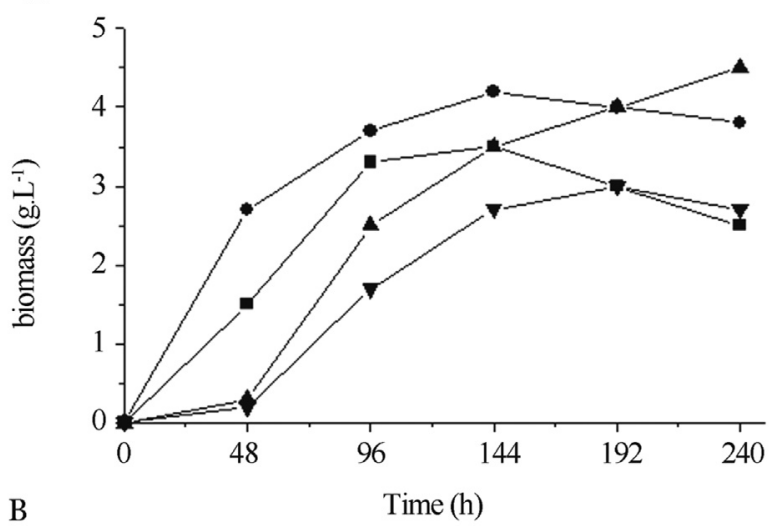

B

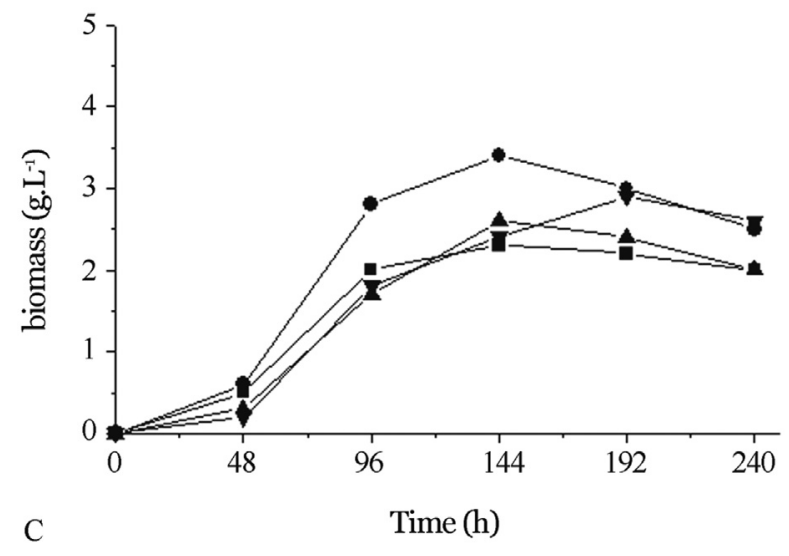

Figure 1 - Biomass production by Dacripionax elegans SXS323 (a), Datronia stereoides MCA167 (b) and Polyporus sp MA128 (c) in medium containing none $(\boldsymbol{\square}), 0.5 \mathrm{~mol} \mathrm{~L}^{-1}(\bullet), 0.6 \mathrm{~mol} \mathrm{~L}^{-1}(\boldsymbol{\Delta})$ and $0.8 \mathrm{~mol} \mathrm{~L}^{-1}(\bullet)$.

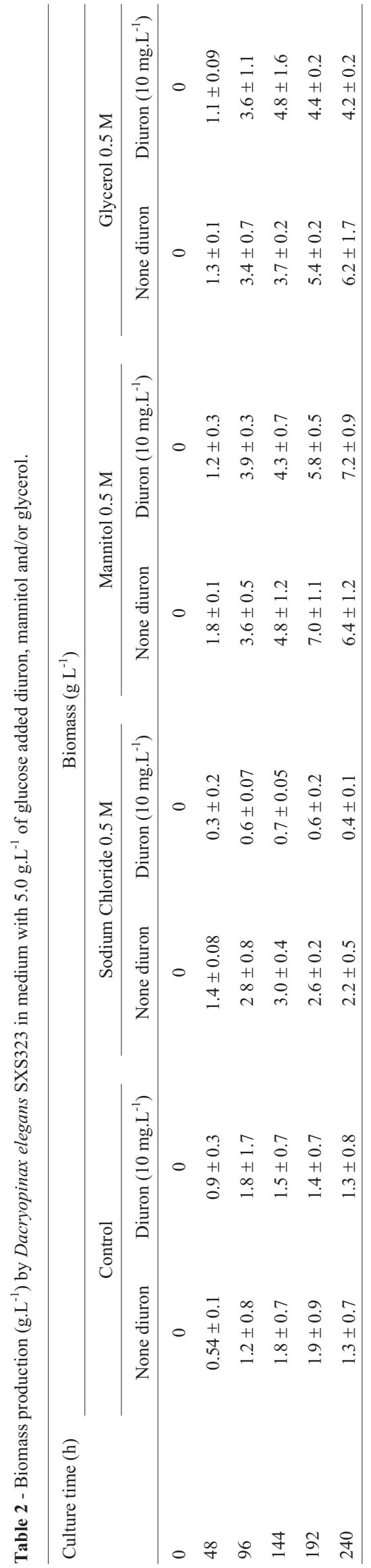



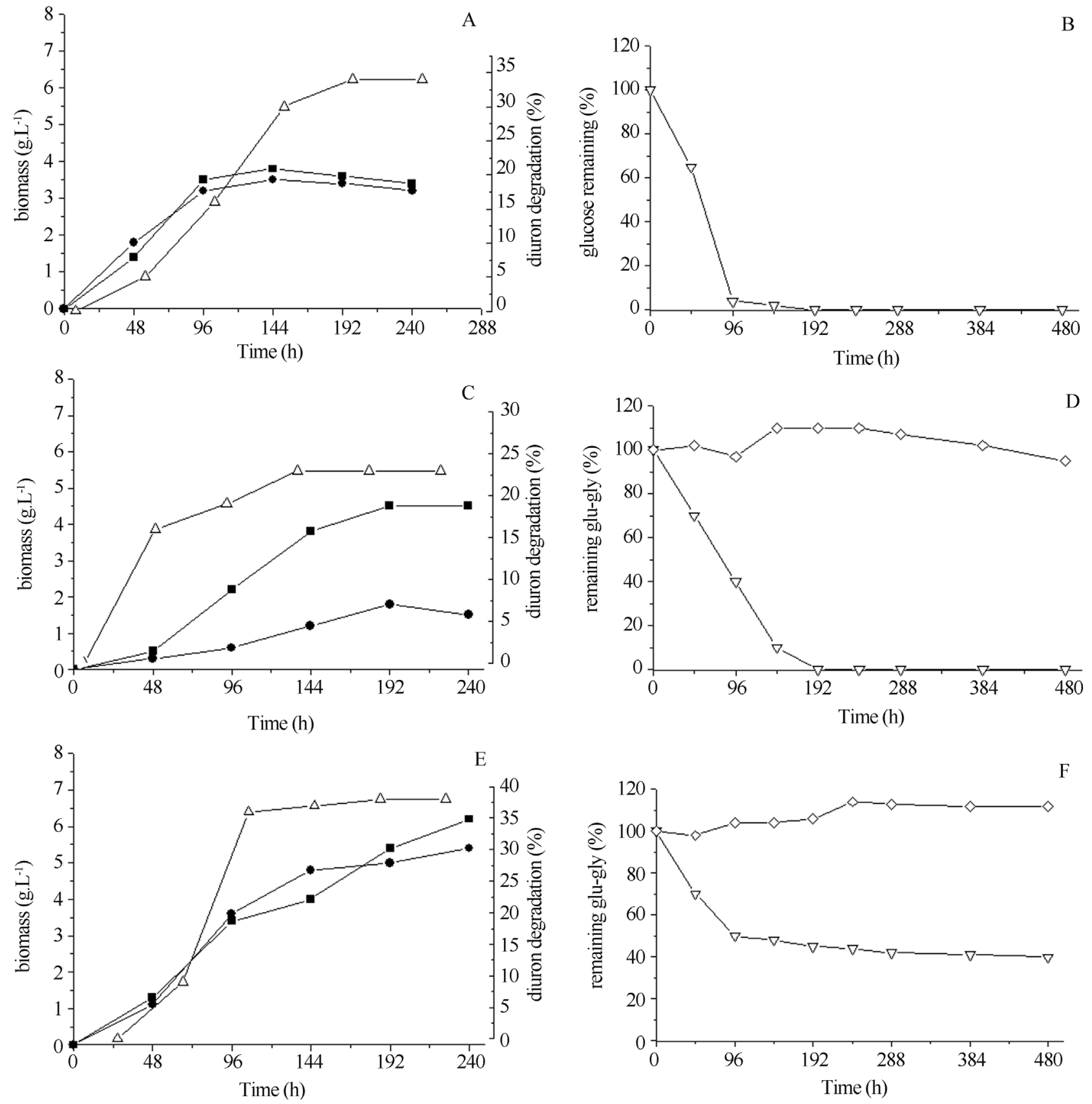

Figure 2 - Production of biomass and diuron degradation by Dacrypionax elegans SXS323. a, b = medium containing $0.03 \mathrm{M}$ of glucose and $10 \mathrm{mg} . \mathrm{L}^{-1}$ of diuron; c, $\mathrm{d}=$ medium containing $0.03 \mathrm{M}$ of glucose, $0.5 \mathrm{M}$ of glycerol and $0.5 \mathrm{M}$ of NaCl; e, $\mathrm{f}=$ medium containing $0.5 \mathrm{M}$ of glucose and $0.5 \mathrm{M}$ of glycerol. $\mathbf{\square}$ = biomass without diuron, $\boldsymbol{O}=$ biomass with diuron, $\Delta=$ diuron degradation; $\diamond=$ remaining glycerol; $\nabla=$ remaining glucose.

medium with $0.03 \mathrm{M}$ of glucose this sugar was totally exhausted in $96 \mathrm{~h}$. When $\mathrm{NaCl}$ at $50 \mathrm{~g} . \mathrm{L}^{-1}$ was added to the medium, the glucose was completely consumed only after $144 \mathrm{~h}$ of cultivation and glycerol level decreased to $96 \mathrm{~h}$ but afterward it increased up to $110 \%$ (Figure $2 \mathrm{~d}$ ). In medium with a higher glucose concentration $(0.5 \mathrm{M})$ and $0.5 \mathrm{M}$ of glycerol, it was observed that the sugar was not totally consumed and $0.2 \mathrm{M}$ were still left after $480 \mathrm{~h}$ of cultivation. Also, glycerol concentration in the medium had an increase of $14 \%$ in the stationary phase of culture $(240 \mathrm{~h}$ ) (Figu- re 2f). The results indicate that the fungus did not take up glycerol in quantity for assimilative metabolism and biomass production not even in absence of glucose. However, variations in glycerol concentrations suggest accumulation and secretion in response to growth phase, osmotic stress and/or possible presence of diuron. It was demonstrated that fungi produce and/or accumulate polyols such as glycerol, mannitol, ribitol from environment, as a compatible solute to maintain the internal $\mathrm{Na}^{+}$below the toxic level in high saline concentration, independently of the ability of 

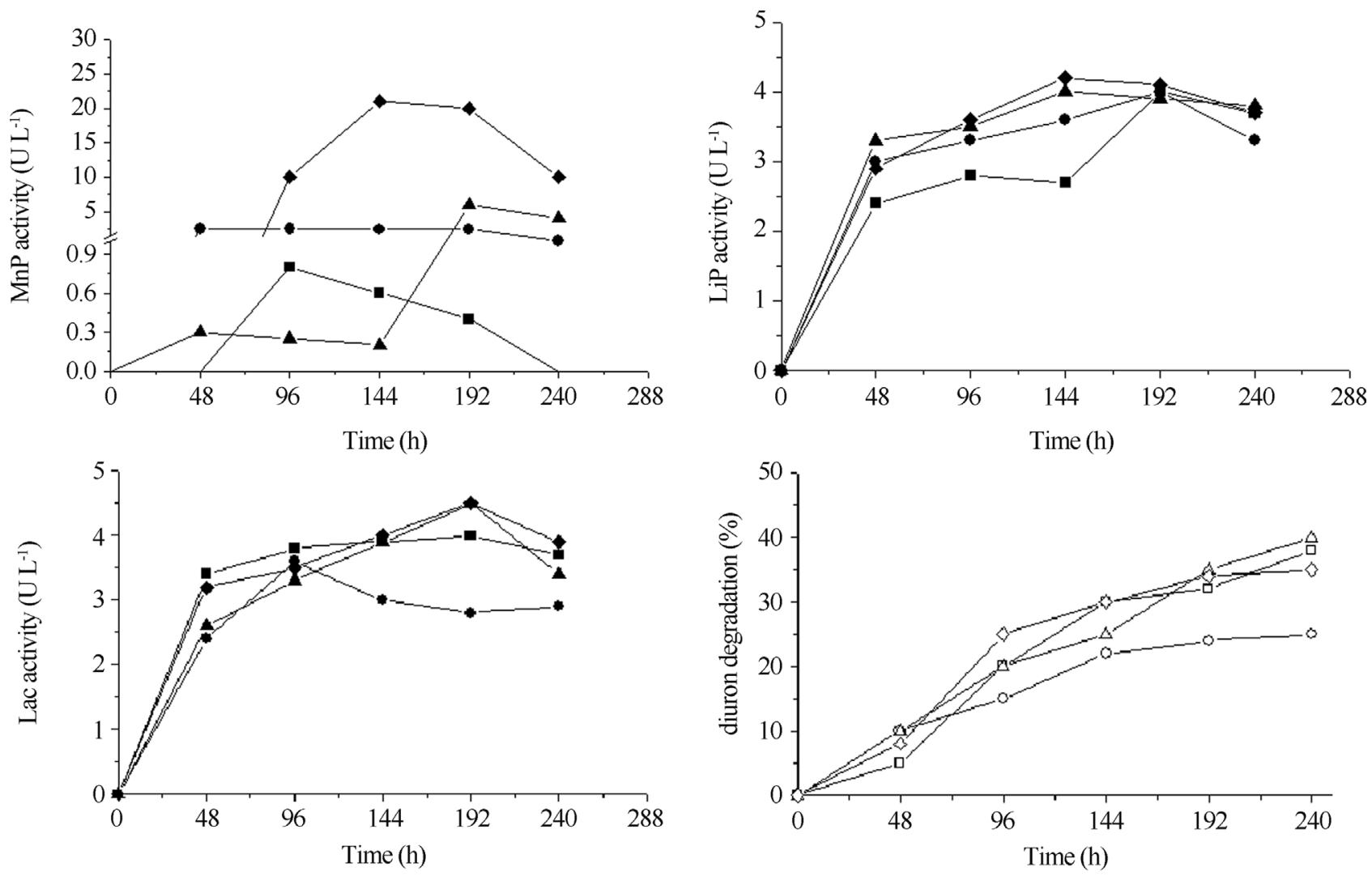

Figure 3 - Manganese peroxidase (a), lignin peroxidase (b), laccase production (c) and diuron degradation (d) by D. elegans in medium control ( $\square$ ), containing $0.5 \mathrm{M}$ of $\mathrm{NaCl}(\mathbf{}), 0.5 \mathrm{M}$ of manitol $(\boldsymbol{\Delta})$ or $0.5 \mathrm{M}$ of glycerol (४).

microorganisms to metabolize them (Adler et al., 1985; Gunde-Cimerman et al., 2009).

D. elegans was able to degrade the diuron in all the culture medium used (Figure 2). In spite of inhibition of the growth by presence of $0.5 \mathrm{M}$ of $\mathrm{NaCl}$ plus diuron (Figure $2 \mathrm{~b}$ ), the diuron degradation was considerable (25\%) compared to control medium (33\%) (Figure 2a). The highest degradation of the herbicide was observed in medium with glycerol (38\%) (Figure 2e). Considering that glycerol improved the fungal growth and the diuron degradation, in spite of it was not had been used as carbon source, we could infer that glycerol roll in the cell is further of osmotic regulation.

\section{Effect of $\mathrm{NaCl}$, mannitol and glycerol on growth and ligninases production by $D$. elegans}

According to Figure $3 \mathrm{a}$, the presence of glycerol and salt in the culture medium increased the manganese peroxidase production by $D$. elegans, but did not influence the lignin peroxidase and laccase production. The action of $\mathrm{NaCl}$ on laccase activity has been described in different ways depending on the microorganism. The presence of low concentrations of $\mathrm{NaCl}$ inhibited the activity of laccase from basidiomycetes Ganoderma lucidum and Pycnosporus sanguineus, but activated laccase from Bacillus halodurans (Ruijssenaars and Hartmans, 2004; Trovaslet et al., 2007; Zilly et al., 2011).
Figure $3 \mathrm{~d}$ show that profiles of ligninase activities are similar to diuron degradation. Laccases are referred as versatile enzymes that degrade a wide range of aromatics compounds like PAHs, PCBs (Johannes and Majcherczyk, 2000; Bending et al., 2002; Keum and Li, 2004; Rodríguez et al., 2004). Nonetheless, the degradation of diuron could be a process independent of ligninases or other enzymes secreted to the medium, as reactions mediated by cytochrome P-450 monooxigenase and epoxide hydrolase (Bezalei et al., 1997; Rabinovich et al., 2004).

In conclusion, basidiomicetes strains responded in different ways to saline concentration in the medium, varying from very sensitive to moderate halophilic profiles. The halophilic $D$. elegans had both an improvement of its growth in presence of $\mathrm{NaCl}$ as well as a positive answer to presence of glycerol in the culture medium with increase in the biomass production and in its ability to degrade diuron, suggesting that glycerol has other rolls in the cell besides to be a compatible solute in mechanisms of response to high salinity.

\section{Acknowledgments}

This work was supported by the Fundação de Amparo a Pesquisa do Estado São Paulo-Fapesp. 


\section{References}

Abou-Elela SI, Kamel MM, Fawzy ME (2010) Biological treatment of saline wastewater using a salt-tolerant microorganism. Desanilisation 250:1-5.

Abrahão MC, Gugliotta AM, Da Silva R, Fujieda RJY, Boscolo M, Gomes E (2008) Ligninolytic activity from newly isolated basidiomycete strains and effect of these enzymes on the azo dye orange II decolourisation. Annals Microbiol 58:427-432.

Adler L, Blomberg A, Nilsano A (1985) Glycerol metabolism and ormoregulation in the salt-tolerant yeast Debaryomyces hansenii. J Bacteriol 162:300-306.

Aitken MD, Irvine RL (1990) Characterization of reactions catalyzed by manganese peroxidase from Phanerochaete chrysosporium. Arch Biochem Bioph 276:405-414.

Bending GD, Friloux M, Walker A (2002) Degradation of contrasting pesticides by white rot fungi and its relationship with ligninolityc potential. FEMS Microbiol Lett 212:59-63.

Bezalei L, Hadar Y, Cerniglia CE (1997) Enzymatic mechanisms involved in phenanthrene degradation by the white rot fungus Pleurotus ostreatus. Appl Environm Microbiol 63:2495-2501.

Buswell JA, Mollet B, Odier E (1984) Ligninolytic enzyme production by Phanerochaete chrysosporium under conditions of nitrogen sufficiency. FEMS Microbiol Lett 25:295-299.

Cameron MD, Timofeevski S, Aust SD (2000) Enzymology of Phanerochaete chrysosporium with respect to the degradation of recalcitrant compounds and xenobiotics. Appl Microbiol Biotechnol 54:751-758.

Cantrell SA, Casillas-Martinez L, Molina M (2006) Characterization of fungi from hypersaline environments of solar salterns using morphological and molecular techniques. Mycol Res 110:962-970.

Cantrell SA, Baez-Fèlix C (2010) Fungal molecular diversity of a Puerto Rican subtropical hypersaline microbial mat. Fungal Ecol 7:402-402.

Castillo G, Demoulin V (1997) NaCl salinity and temperature effects on growth of three wood-rotting basidiomycetes from a Papua New Guinea coastal forest. Mycol Res 101:341-344.

Cerniglia CE (1997) Fungal metabolism of polycyclic aromatic hydrocarbons: past present and future applications in bioremediation. J Ind Microbiol Biotechnol 19:324-333.

Dellamatrice PM, Monteiro RTR (2004) Isolation of diurondegrading bacteria from treated soil. Braz Arch Biol Technol 47:999-1003.

Giacomazzi S, Cochet N (2004) Environmental impact of diuron transformation: a review. Chemosphere 56:1021-1032.

Gianfreda L, Rao MA (2004) Potential of extra cellular enzymes in remediation of polluted soils: a review. Enzyme Microb Technol 35:339-354.

Glenn JK, Akileswaran L, Gold MH (1986) Mn (II) oxidation is the principal function of the extracellular Mn-peroxidase from Phanerochaete chrysosporium. Arch Biochem Bioph 251:688-696,

Gostinc C, Lenassi M, Gunde-Cimerman N, Plemenitas A (2011) Fungal Adaptation to Extremely High Salt Concentrations. Adv Appl Microbiol 77:71-96.

Gunde-Cimerman N, Ramos J, Plemenitas A (2009) Halotolerant and halophilic fungi-Review. Mycol Res 113:1231-1241.
Johannes C, Majcherczyk A (2000) Natural Mediators in the Oxidation of Polycyclic Aromatic Hydrocarbons by Laccase Mediator Systems. Appl Environm Microbiol 66:524-528.

Keum YS, Li QX (2004) Fungal laccase-catalyzed degradation of hydroxyl polychlorinated biphenyls. Chemosphere 56:2330.

Kirk PM, Cannon PT, David JC, Stalpers JA (2001). Ainsworth and Bisby's Dictionary of the fungi, $9{ }^{\text {th }} \mathrm{Ed}$. CAB International, Oxon, UK.

Kivisto A, Karp M (2011) Halophilic anaerobic fermentative bacteria-Review. J Biotechnol 152:114-124.

Leitão AL, Duarte MP, Santos-Oliveira J (2005) Degradation of phenol by a halotolerant strain of Penicillium chrysogenum. Int Biodeg Biorem 59:220-225.

Lenassi M, Zajc J, Gostincar C, Gorjan A, Gunde-Cimerman N, Plemenita A, (2011) Adaptation of the glycerol-3-phosphate dehydrogenase Gpd1 to high salinities in the extremely halotolerant Hortaea werneckii and halophilic Wallemia ichthyophaga. Fungal Biol 115:959-970.

Li X, Kondo R, Sakai K (2002) Studies on hypersaline-tolerant white-rot fungi I: screening of lignin-degrading fungi in hypersaline conditions. J Wood Sc 48:147-152.

Li X, Kondo R, Sakai K (2003) Studies on hypersaline-tolerant white-rot fungi IV: effects of $\mathrm{Mn}^{2+}$ and $\mathrm{NH}_{4}{ }^{+}$on manganese peroxidase and Poly R-478 decolorization by the marine isolate Phlebia sp. MG-60 under saline conditions. J Wood Sc 49:355-360.

Miller GL (1959) Use of dinitrosalisylic acid reagent for determination of reducing sugar. Anal Chem 31:426-428.

Miyazaki Y, Hiraide M, Shibuya H (2007) Molecular cloning of functional genes for high growth-temperature and salt tolerance of the basidiomycetes Formitopsis pinicola isolated in the mangrove forest in Micronesia. Bioc Biotechnol Biochem 7:273-278.

Moubasher AH, Abdel-Hafez SI, Bagy MMK, Abdel-Satar MA (1990) Halophilic and halotolerant fungi from cultivated dessert and salt marsh soils from Egypt. Acta Mycol 26:65-81.

Petrovic U, Gunde-Cimermen N, Plemennitas A (2002) Cellular responses to environmental salinity in the halophilic black yeast Horteae werneckii. Mol Microbiol 45: 665-672.

Plemennita A, Vaupotic T, Lenassi M, Kogej T, Gunde-Cimerman N (2008) Adaptation of extreme halotolerant black yeast Hoetaea werneckii to increased osmolarity: a molecular perspective at a glance. Studies Mycol 61:67-75.

Rabinovich ML, Bolobova AV, Vasil'chenko LG (2004) Fungal decomposition of natural aromatic structures and xenobiotics: a review. Appl Biochem Microbiol 40:1-17.

Rodríguez E, Nuero O, Guillén F, Martínez AT, Martínez MJ (2004) Degradation of phenolic and non-phenolic aromatic pollutants by four Pleurotus species: the role of laccase and versatile peroxidases. Soil Biol Biochem 36:909-916.

Ruijssenaars HJ, Hartmans SA (2004) Cloned Bacillus halodurans multicopper oxidase exhibiting alkaline laccase activity. Appl Microbiol Biotechnol 66: 177-182.

Santos SX, Carvalho CC, Bonfá MRL, Silva R, Gomes E (2004) Screening for pectinolytic activity of wood-rotting Basidiomycetes and characterization of the enzymes. Folia Microbiol 49:46-52.

Sørensen SR, Bending GD, Jacobsen CS, Walker A, Aamand J (2003) Microbial degradation of isoproturon and related 
phenylurea herbicides in and below agricultural fields. FEMS Microbiol Rev 45:1-11.

Tangavelu V, Tang J, Ryan D, Valix M (2006) Effect of saline stress on fungi metabolism and biological leching of weathered saprofite ores. Mineral Engen 19:1266-1273.

Tien M, Kirk TK (1988) Lignin peroxidase of Phanerochaete chrysosporium. Methods Enzymol 161:238-249.

Tixier C, Bogaerts P, Sancelme M, Bonnemoy F, Twagilimana L, Cuer A, Bohatier J, Veschambre H (2000) Fungal biodegradation of a phenylurea herbicide, diurom: structure and toxicity of metabolites. Pest Managem Sc 56:455-462.
Trovaslet M, Enaud E, Guiavarc'h Y, Corbisier AM, Vanhulle S (2007) Potential of a Pycnoporus sanguineus laccase in bioremediation of wastewater and kinetic activation in the presence of anthraquinonic acid dye. Enzyme Microb Technol 43:368-376.

Zilly A, Coelho-Moreira JS, Bracht A, Souza MCG, Carvajal AE, Koehnlein EA, Peralta RM (2011) Influence of $\mathrm{NaCl}$ and $\mathrm{Na}_{2} \mathrm{SO}_{4}$ on the kinetics and dye decolorization ability of crude laccase from Ganoderma lucidum. Int Biodeg Bioderem 65:340-344.

All the content of the journal, except where otherwise noted, is licensed under a Creative Commons License CC BY-NC. 